\title{
Family Medicine: A Complete Relationship
}

\author{
Bret Kilker, Medical Student Year 4
}

As a medical student, when starting a clerkship you always have some idea of what you are going to experience. In psychiatry, you anticipate crazy people and even crazy psychiatrists. In surgery, you think of type-A surgeons and unconscious patients. For family medicine I thought of noncompliant patients with chronic problems and incredibly frustrating insurance problems with equally frustrated doctors trying to stay afloat. Unfortunately, I found that those things are present in family medicine, albeit to varying degrees. However, my experience seemed to stress something else entirely. All the negative aspects were far overshadowed by the omnipresent feeling of friendship and family I felt stemming from the family physician's ability and duty to tend to the patient's biological, psychological, emotional, and overall health. I was impressed with this "complete" care and I witnessed how it created a unique patient-physician relationship. $\mathrm{Pa}-$ tients in the family medicine office are not like patients in the hospital or even the subspecialty clinic. They are known to you, they are familiar, and they are personal. Family medicine physicians don't just provide a diagnosis and a prescription. They are the utmost providers of the bio-psychosocial model of medicine. They skillfully utilize personal interactions as a vehicle through which to obtain information and provide therapy, all the while making it seem like a conversation between 2 friends.

I first began to sense the "complete" health care provided by family medicine doctors early in my first week in family medicine when I found myself presenting a patient to my attending as I always

This article was externally peer reviewed.

Submitted 11 January 2008; revised 10 April 2008; accepted 11 April 2008.

From the Keck School of Medicine, University of Southern California, Los Angeles California.

Funding: none.

Conflict of interest: none declared.

Corresponding author: Bret Kilker, Keck School of Medicine, University of Southern California, 29522 Los Osos Drive, Laguna Niguel, CA 92677 (E-mail: bkilker@usc.edu). had: "Patient is a 42-year-old Hispanic female who presents with complaints of cough, SOB, fever-" The doctor stopped me. "Wait, who is the patient?" I stated her name and the doctor asked how her kids were doing. "I didn't ask," I remarked, rather embarrassed for not inquiring about something that it appeared I should have known. The doctor went on to explain that her children were a major source of stress to her. They were teenagers and getting in trouble and, as a single mother, the patient's depression, anxiety, diabetes, and other health issues were all exacerbated when her kids were acting out. We went in to see the patient and, sure enough, one of her sons had been suspended from school for drug use. "I'll talk to him when he comes in again," the doctor reassured the patient, "Now let's get you well again." This scenario happened more than I can remember during the clerkship. I would take what I thought was a detailed history and the attending would ask about something else from the patient's life after I divulged the name of the patient. I realized that the patientphysician relationship was much deeper in family medicine than in other specialties. And all it takes to reacquaint the doctor with the patient is a simple name.

The idea of presenting a patient's name had been foreign to me. In other rotations, it was commonplace to use age, ethnicity, and gender as identifiers so my attending could scan through epidemiologic risk factors in his or her head. In family medicine all I have to say is the patient's name and that person is known to the doctor. The patient's medical history may be recalled but more importantly, knowledge and understanding of the complete person seems to flood the doctor's mind. I had replaced vague descriptors and risk factors with something intimate and unique: an individual's name. It was a simple yet powerful gesture and a microcosm of the type of health care that is practiced in family medicine offices. And often times, this enabled the physician to quickly and accurately determine the root of the patient's complaint. Fam- 
ily medicine doctors embrace a very special relationship with their patients that utilizes a genuine friendship to deliver comprehensive health care.

I also was able to sample this friendship for myself and, unbeknownst to me at the time, provide the patient with some social support. This was made possible when I saw the same patient twice during my clerkship and I found out that he has diabetes and that he "requires" check-ups about every 3 weeks. When I asked the doctor about the necessity of the frequent visits he said, "Oh, of course, they are not entirely necessary, but for some of my older patients, coming to see me is the highlight of their week." He explained that for some of the elderly, their children are on their own and have their own families, many of their friends have died or have been moved into nursing homes, and they don't work anymore. My preceptor told me that for some of his patients, he is their most accessible friend and a major source of social interaction. The patients come not only for health care, but also for companionship. A doctor's visit can provide a reason to get up early, a reason to get dressed, a reason to take care of oneself, and an outlet to vent your complaints about health, family, work, and life in general. I could tell that the doctor wanted more than to simply monitor the patient's diabetes; he wanted to keep his patient socially healthy, which might also help his physical health.

The close relationship that exists between patient and physician in family medicine enables the doctor to care for the patient's biological, psychological/emotional, and social health, but I learned that patients can care just as much about their doctor. During my rotation, an elderly man came in for a checkup. I didn't know it at the time, but this gentleman had been seeing the doctor since residency. In fact, the man's whole family had received their medical care from my preceptor, including the man's deceased wife. The visit itself consisted mainly of small talk and eventually the man's wife was brought up. The man and my preceptor shared some memories and I saw tears welling up in the eyes of the doctor. I don't know what the doctor was thinking about, but I could tell how much his patients meant to him and, conversely, how much the doctor meant to the patient. The patient seemed to feel better after talking about his wife. I was struck by the notion that the doctor had delivered a kind of emotional therapy to his patient in addition to addressing his medical problems.

Family medicine enables a physician to develop relationships with patients unlike any specialty that I have experienced thus far. It is so different from the surgeons who perform their work on an unconscious patient. Nor is it like psychiatrists who must keep their patients at arm's length to prevent the development of unhealthy attachments. As a family medicine physician you are encouraged and even expected to develop an intimate knowledge of the person you see in your office so you can provide care for the complete person, and sometimes they care about you as a complete person too. It was refreshing to see a specialty that embraces the bio-psycho-social model so wholeheartedly. Also, it was revealing to witness how the physician goes about doing this: with empathy, a deep emotional connection, and an intimate knowledge of the patient extending well beyond the realm of biology. The patient-physician relationship in family medicine is very personal for both parties. Family medicine is aptly named. The physician welcomes the patient into his or her medical practice and, in turn, the physician and patient become family. 